\title{
A MINERAÇÃO EM MINAS GERAIS: UMA ANÁLISE DE SUA EXPANSÃO E OS IMPACTOS AMBIENTAIS E SOCIAIS CAUSADOS POR DÉCADAS DE EXPLORAÇÃO
}

\section{Mining in Minas Gerais: an analysis of its expansion and the environmental and social impacts caused by decades of exploration.}

\author{
Vanessa Leite Rezende \\ Universidade Federal de Minas Gerais, Belo Horizonte, Minas Gerais, Brasil. \\ vanessa.leite.rezende@gmail.com
}

Artigo recebido em 15/04/2016 e aceito para publicação em 18/11/2016

RESUMO: O estado de Minas Gerais vem sofrendo com a exploração de minério desde o começo da colonização no Brasil. Apesar disso, ainda hoje é o estado que mais possui reservas minerais, o que gera um embate entre produção mineral e conservação ambiental, uma vez que a extração do minério gera desmatamento e outros impactos ambientais. O objetivo desse trabalho foi obter um panorama sobre a expansão da mineração e os impactos resultantes dessa atividade ao longo dos anos no estado. Os resultados mostraram que nas últimas décadas houve um grande aumento da expansão de minas no estado, bem como impactos ambientais e de saúde pública nas cidades que abrigam minerações mais antigas. Assim, conclui-se que por ser uma fonte de economia importante para o Brasil, é preciso rever a política ambiental das grandes minerações, bem como aumentar a fiscalização por parte dos órgãos públicos para que possamos assegurar as fontes de minério, bem como qualidade ambiental para as futuras gerações.

Palavras-chaves: Desenvolvimento sustentável; Unidades de conservação; Extração mineral; Meio ambiente.

ABSTRACT: The state of Minas Gerais has been suffering from the mineral exploration since inception of colonization in Brazil. Despite this, today is the state that has more mineral reserves, which creates an encounter between mineral production and environmental conservation, since the mineral extraction generates deforestation and other environmental impacts. The aim of this study was to obtain an overview of the expansion of mining and the resulting impacts of mining over the years in the state. The results showed that in recent decades there has been a large increase in the expansion of mines in the state, as well as environmental and public health impacts in cities that harbor the oldest mining. Thus, it was concluded that to be an important source of savings for Brazil, it becomes necessary to review the environmental policy of large mining and increase supervision by the public agency so that we can ensure the sources of mineral and quality environmental for future generations.

Keywords: Sustainable development; Conservation units; Mineral extraction; Environment. 
A mineração em Minas Gerais: uma análise de sua expansão e os impactos ambientais e sociais causados por décadas de exploração

Vanessa Leite Rezende

\section{INTRODUÇÃO}

O estado de Minas Gerais, quando falamos em mineração, faz toda a honra ao seu nome. A chegada de aventureiros, grupos organizados e membros da corte portuguesa no Brasil a procura de ouro no estado, começou nos primórdios do século XVII (SOBREIRA E FONSECA, 2001), e ainda hoje Minas Gerais é o estado que mais produz minério. De acordo com Tonietto e Silva (2011), as reservas de minérios medidas e indicadas no Brasil, totalizam 28,9 bilhões de toneladas, sendo que, desses, $67 \%$ está localizado no estado de Minas Gerais. Pelas estatísticas do Departamento Nacional de Produção Mineral (DNPM, 2014), Minas Gerais se situa como o maior estado produtor de minério do Brasil, com $47,01 \%$ da produção nacional. De acordo com os dados obtidos no site do DNPM, o estado de Minas Gerais produziu o equivalente a 800.684.546,79 reais em 2014. Deve-se lembrar de que, devido às limitações do sistema de coleta de informações do DNPM e a presença de parcela significativa de lavras informais, pode-se considerar que as estatísticas oficiais estejam subestimadas.

Estes dados se aplicam especialmente para a região do Quadrilátero Ferrífero, uma área geológica cuja forma se assemelha a um quadrado, e que perfaz uma área de aproximadamente $7000 \mathrm{~km}^{2}$, estendendo-se entre Ouro Preto a sudeste, e Belo Horizonte, a noroeste (ROESER E ROESER, 2010). Essa região apresenta embasamento e áreas circunvizinhas compostas de gnaisses tonalítico-graníticos de idade arqueana ( $>2.7$ bilhões de anos; ROESER E ROESER, 2010). Atualmente, além de abrigar grandes minerações de ferro e ouro, o Quadrilátero Ferrífero também abriga vários empreendimentos de mineração que exploram jazidas de outros tipos de rochas e minerais como, por exemplo, topázio e bauxita (MARENT et al., 2011).

Mesmo com a grande extração mineral que vem ocorrendo por muitos anos no estado, algumas áreas ainda se encontram em condições ambientais de notável conservação, com pouca ou quase nenhuma atividade antrópica, como ex. a Serra do Gandarela (MARENT et al., 2011). Essa Serra sofreu um embate entre a mineração e a criação de um parque, devido à sua elevada biodiversidade e ao montante de mananciais que abastecem a região metropolitana de Belo Horizonte. Recentemente o parque foi criado com o objetivo de preservar o patrimônio biológico, geológico e hidrológico da região, porém o desenho do parque sofre contestação da comunidade local (http://www.aguasdogandarela.org/, 2014).

$\mathrm{O}$ estágio atual da atividade mineraria exige instrumentos de controle que condizem com o desenvolvimento sustentável, utilizando-os em benefício do desenvolvimento regional e do envolvimento requerido por esta atividade com a sociedade na qual está inserida. A mineração pode ser uma atividade positiva para os municípios, não apenas pelos impostos que recolhe, mas pelos empregos diretos e indiretos que gera. Assim, devido ao fato da mineração ser uma atividade econômica fundamental, sendo uma das atividades mais importantes para a economia do Brasil (BARRETO, 2001) e servindo como base para importantes atividades econômicas, a dificuldade no controle da disponibilidade futura dos recursos minerais coloca em risco a competitividade ou mesmo, em determinadas circunstâncias, o próprio desenvolvimento sustentado das cadeias produtivas relacionadas (CABRAL JUNIOR et al., 2008).

\section{MATERIAL E MÉTODOS}

A fim de obter um panorama da expansão da mineração no estado de Minas Gerais (Fig1), analisamos através do programa Qgis 2.4.0 (disponível em: http://www.qgis.org), o shapefile disponível no site do DNPM (http://sigmine.dnpm.gov.br) com os dados dos processos de mineração no estado desde o ano de 1935 até o ano de 2014. Para calcular a área afetada pela expansão da mineração, comparamos a área $\mathrm{em} \mathrm{km}^{2}$, concedida pela mineração ou para estudo de mineração para o ano de 2014 , e a área afetada pela mineração durante os anos desde 1980. Comparamos as áreas que foram requeridas pela mineração para cada período de 10 anos (1980-1989, 1990-1999, 2000-2009 e 2010-2014), e as áreas somadas (área disponível até 1980, 1990, 2000 e 2010). Para obter um panorama sobre as áreas de mineração que podem estar dentro ou próximo de 
Unidades de Conservação, sobrepusemos o shapefile de mineração do DNPM, com o shapefile de Unidades de Conservação disponível no site do IBGE (disponível em: < http://www.ibge.gov.br>).

Pesquisamos também através de artigos científicos publicados, monografias, dissertações e teses o que já foi publicado sobre os impactos ambientais da mineração no estado de Minas Gerais. A pesquisa foi realizada principalmente pela internet através de diferentes bases de dados (ex: Google acadêmico e Scopus), usando palavras-chave tais como, mineração e biodiversidade, mineração em Minas Gerais, mineração no quadrilátero ferrífero e mineração e Mata Atlântica.

\section{RESULTADOS E DISCUSSÃO}

Somente no ano de 2014, foram liberados $19913 \mathrm{~km}^{2}$ para fase de concessão, desses 712.60 $\mathrm{km}^{2}$ já estão disponíveis para mineração. Quando comparamos os resultados por período, de 2010 até o presente momento foram requeridos $149947,9 \mathrm{~km}^{2}$ para a mineração, desses $32411,32 \mathrm{~km}^{2}$ foram liberados. No período anterior (2000-2009) $84992,81 \mathrm{~km}^{2}$ foram requeridos pela mineração, desses 22815,05 $\mathrm{km}^{2}$ foram liberados. Quando comparamos com os períodos anteriores (de 1935 a 1999) foram requeridos $23669,99 \mathrm{~km}^{2}$, e $9140,13 \mathrm{~km}^{2}$ disponíveis para a mineração, o que demonstra o expressivo aumento nos últimos 20 anos (Tabela 1; Figura 1).

Tabela 1: Valores de área requerida pela mineração por períodos de anos, desde o ano de 1935.

\begin{tabular}{|l|l|l|l|}
\hline \multicolumn{1}{|c|}{ Ano/Período } & $\begin{array}{c}\text { Fase (requerimento } \\
\text { de pesquisa) }\end{array}$ & \multicolumn{1}{|c|}{ Fase (disponibilidade) } & \multicolumn{1}{|c|}{ Total $\left(\mathrm{Km}^{2}\right)$} \\
\hline 2014 & 19200,59 & 712,6 & 19913,42 \\
\hline $2010-2014$ & 117534,22 & 32411,32 & 149947,9 \\
\hline $2000-2009$ & 61953,2 & 23039,61 & 84992,81 \\
\hline $1990-1999$ & 7378,76 & 1547,59 & 8926,35 \\
\hline $1980-1889$ & 6037,38 & 2600,7 & 8638,08 \\
\hline $1970-1979$ & 1031,54 & 2500,43 & 3531,97 \\
\hline $1960-1969$ & 27,23 & 576,03 & 603,26 \\
\hline $1950-1959$ & 11,94 & 386,8 & 398,74 \\
\hline $1935-1949$ & 36,43 & 1535,15 & 1571,58 \\
\hline
\end{tabular}


A mineração em Minas Gerais: uma análise de sua expansão e os impactos ambientais e sociais causados por décadas de exploração

Vanessa Leite Rezende

Figura 1 - Mapa da expansão da mineração no estado de Minas Gerais durante desde os anos 1980 até o desenho atual.

Expansão da mineração durante os últimos periodos de 10 anos
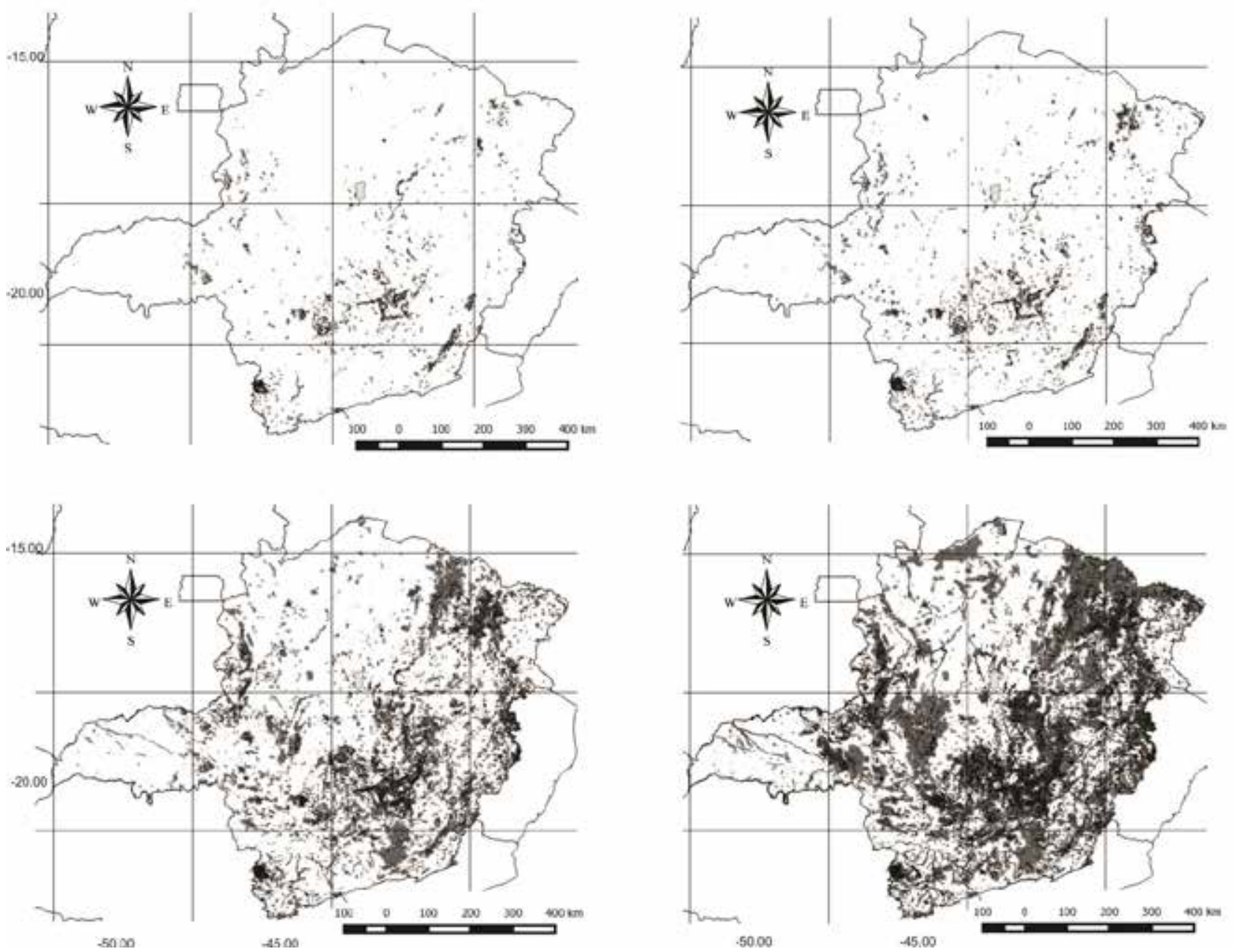

a) área de mineração no período de 1980 a 1989; b) área de mineração no período de 1990 a 1999; c) área de mineração no período de 2000 a 2010; d) área de mineração de 2010 a 2014.

De acordo com os dados do DNPM (2014), atualmente no estado de Minas Gerais, há 258610,7 $\mathrm{km}^{2}(44,09 \%$ do estado) em alguma fase de concessão para mineradoras, sendo que, desses, 64530,62
(11,00\% do estado) já foram concedidos ou liberados (Figura 2). No total foram registrados 40614 empreendimentos, desses a maior parte $(4908 ; 12,08 \%)$ são de minério de ferro. 
Figura 2 - Expansão da mineração no estado de Minas Gerais.

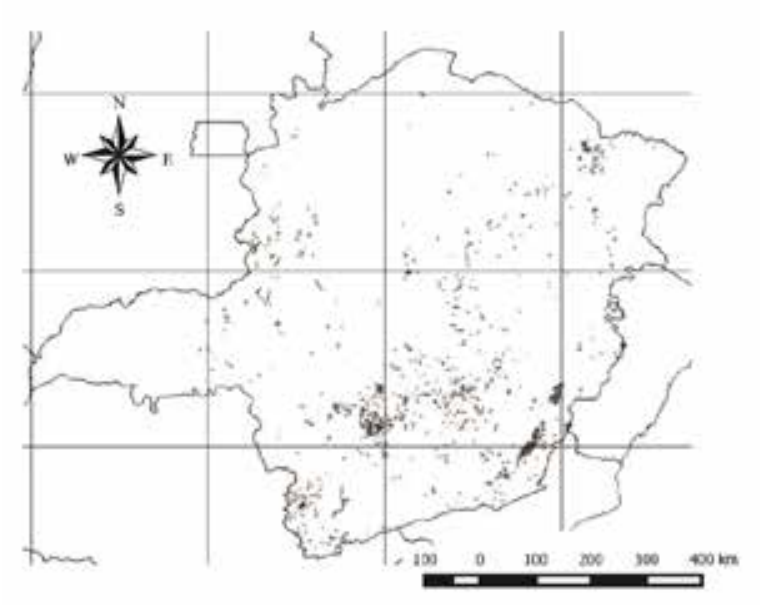

Expansâo da mineração por cada periodo de 10 anos
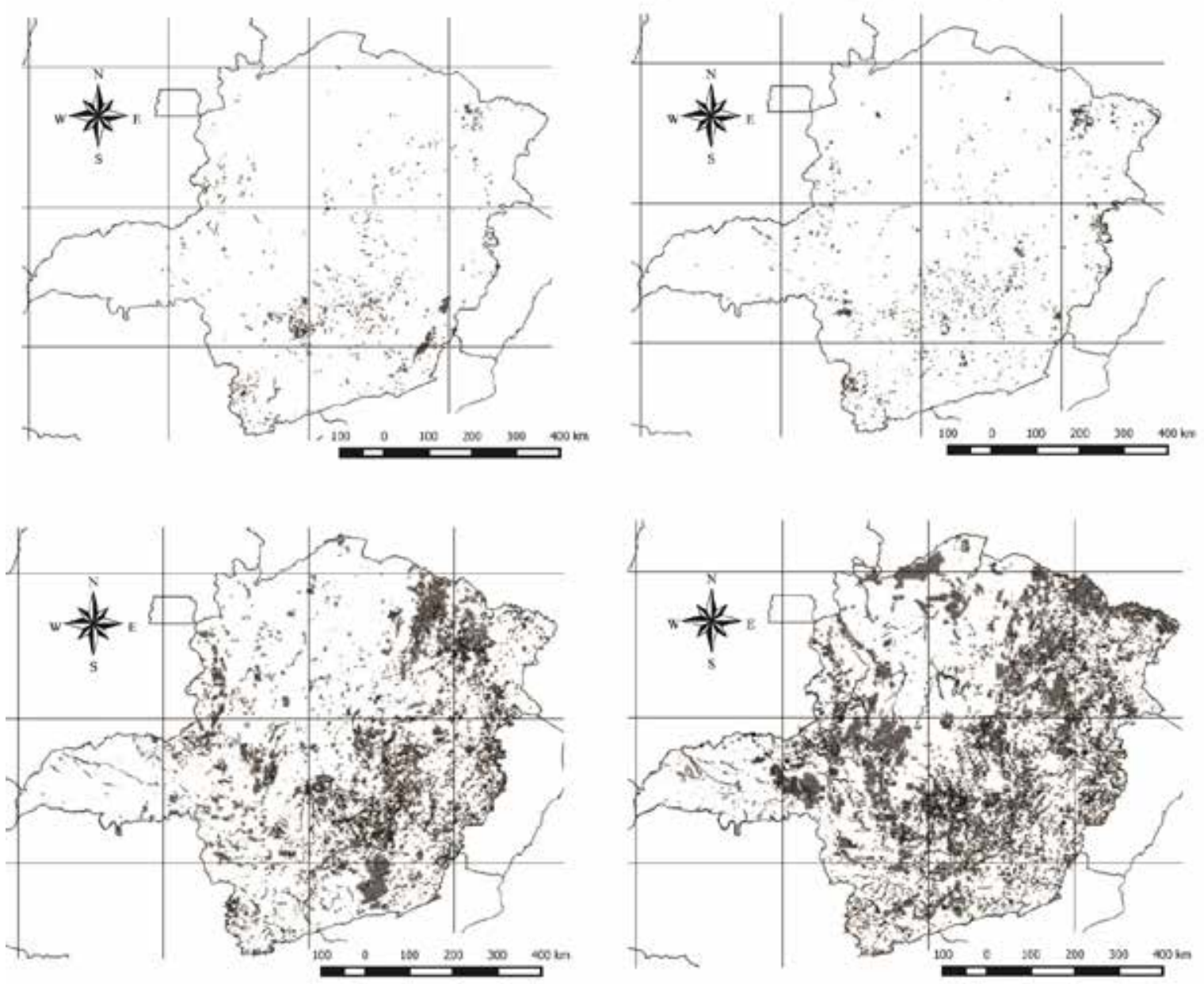

Os mapas mostram quanto foi expandido em cada período de 10 anos. a) o aumento da mineração de 1980 a 1989 ; b) o aumento da mineração de 1990 a 1999; c) o aumento da mineração de 2000 a 2009; o aumento da mineração de 2010 a 2014.

O grande aumento da mineração nos últimos anos pode ser devido ao período de estagnação da mineração nas décadas finais do século XX, onde pode-se ressaltar a perda da importância estratégica das commodities metálicas na economia global e a necessidade da incorporação dos princípios de sustentabilidade ambiental no aproveitamento dos recursos minerais (CABRAL JUNIOR et al., 2008). E, a partir de 1990, a presença de novos entrantes, destacadamente o acesso agressivo da China no mercado mineral, favoreceu o excesso de oferta e acentuou a tendência de queda generalizada dos preços dos minérios e metais (CABRAL JUNIOR et al., 2008), o que acelerou a sua produção.
Ao analisar a área de mineração que está dentro ou próximo a unidades de conservação (Figura 3), podemos perceber, principalmente, na área do Quadrilátero Ferrífero, que há uma forte pressão por parte das mineradoras no entorno dessas áreas. Diniz et al., (2014), analisaram a expansão da mineração na área da APA SUL, e concluíram que a menor expansão mineraria ocorreu entre os anos de 1994 a 2000, podendo estar diretamente relacionado com a criação da APA no ano de 1994, que atuou como um inibidor da exploração mineraria no interior da unidade de conservação; e a maior expansão mineraria, entre os anos de 2000 a 2011, que pode estar relacionada a atuação da APA, permitindo as explorações de forma sustentável. 
A mineração em Minas Gerais: uma análise de sua expansão e os impactos ambientais e sociais causados por décadas de exploração

Vanessa Leite Rezende

Figura 3 - Mapa de sobreposição das áreas de mineração do estado de Minas Gerais (DNPM, 2014) com as Unidades de Conservação presentes na área.

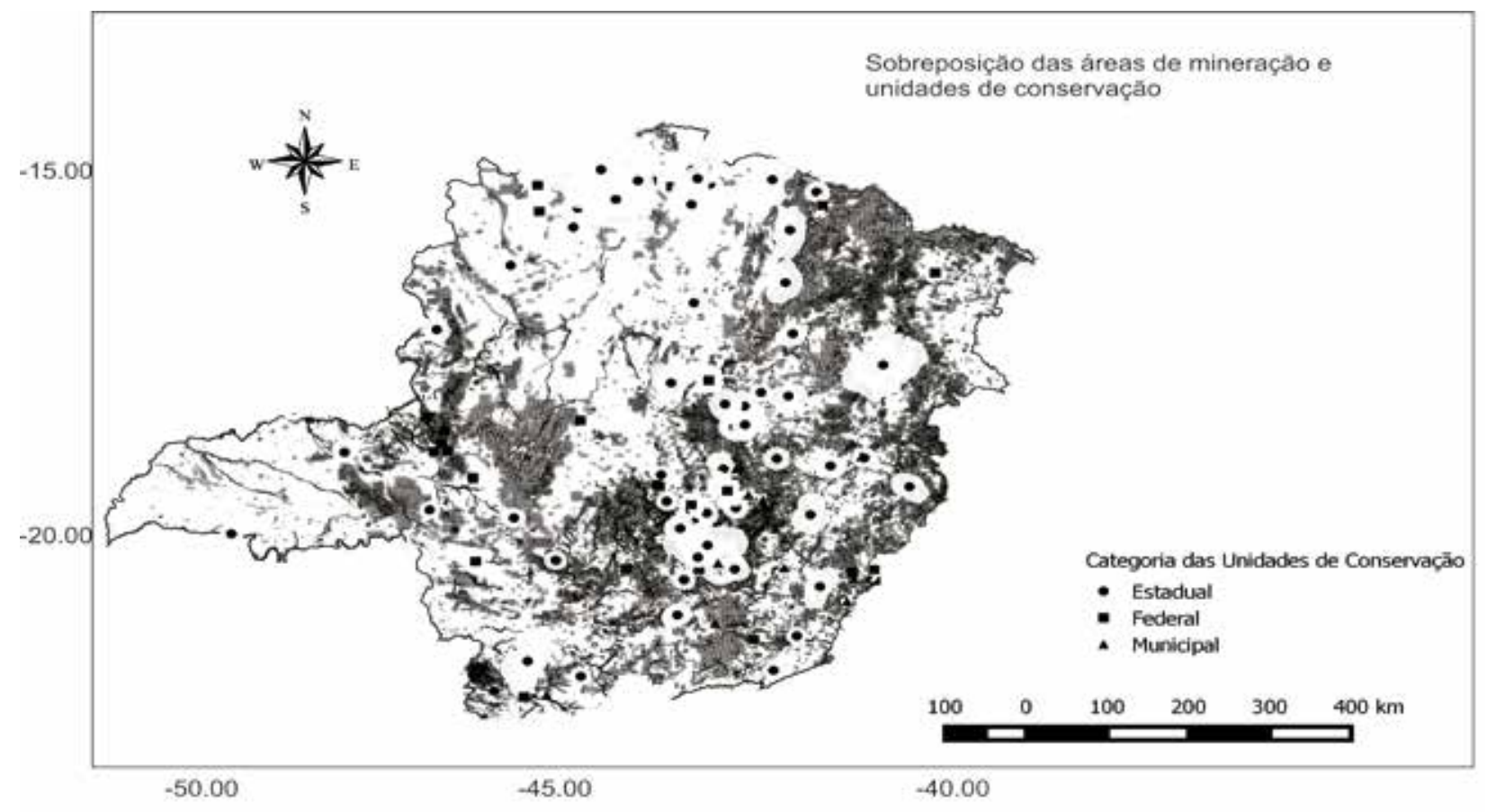

As Unidades de Conservação estão divididas em Federal, Estadual e Municipal.

Segundo dados da fundação SOS Mata Atlântica (2014), apesar de liderar a lista de desmatamento por unidade federativa do Brasil, Minas Gerais apresentou redução de $22 \%$ na taxa de desmatamento no ano passado. De acordo com a Fundação SOS Mata Atlântica (2014), a queda é resultado de uma moratória do governo do estado, que desde junho de 2013 impede a concessão de licenças e autorizações para supressão de vegetação nativa no bioma Mata Atlântica. A ação foi autorizada pelo Governo de Minas Gerais após solicitação da Fundação, apresentada em ofício protocolado em 10 de junho de 2013. Assim, através dessas iniciativas do governo do estado podemos esperar taxas menores de desmatamento para os próximos anos.

\section{IMPACTOS DA MINERAÇÃO NO ESTADO DE MINAS GERAIS}

De acordo com Bitar (1997) a mineração é responsável por promover uma diversidade de efeitos não desejados, os impactos de grande relevância seriam: alterações ambientais, conflitos de uso do solo, depreciação de imóveis circunvizinhos, geração de áreas degradadas e transtornos ao tráfego urbano. Estes provocam conflitos com a comunidade, devido à falta de interesse do empreendimento em atender as necessidades da população.

Silva e Souza (2002) avaliaram a vulnerabilidade ambiental da cidade de Itabira, sede da mineradora Vale, sobre os impactos e riscos socioambientais advindos da mineração em área urbana, e concluíram que: "A questão ambiental em Itabira, torna-se cada vez mais séria na medida em que, hoje, as minas aproximam-se dos bairros e os veios de minério tornam-se mais profundos." Segundo esses autores apesar do aumento na consciência ambiental da sociedade, e a maior atuação do ministério Público em relação à cobrança do cumprimento das leis ambientais pela mineradora, a situação de vulnerabilidade ambiental na cidade persiste.

A agressão da atividade exploratória expõe a comunidade a grandes ruídos provocados pelo desmonte de material consolidado (maciços rochosos e terrosos muito compactados) que é feito através de explosivos, resultando prejuízos à tranquilidade pública (SILVA, 2007), e gerando impactos à fauna local. O trafego intenso de veículos pesados, carregados de minério, também 
A mineração em Minas Gerais: uma análise de sua expansão e os impactos ambientais e sociais causados por décadas de

emitem ruídos, além da frequente deterioração do sistema viário da região. Pontes et al., (2013) comenta que além do efeito não desejado do ruído provocado pelo uso de explosivo, este também pode expor os trabalhadores a grandes riscos de acidentes, até mesmo a morte.

Em Canaã dos Carajás (PA), moradores das comunidades localizadas no entorno do Projeto Sossego manifestam suas preocupações em relação à Vale, especialmente no que se refere aos impactos ambientais causados pelo empreendimento. As vibrações e os ruídos causados pela extração de cobre atingem a todos: pessoas e animais, sem que a empresa e o poder público local tomem medidas para a resolução desse problema. Moradores de comunidades vizinhas ao Projeto Sossego dizem que por causa do forte ruído provocado pelas máquinas e pela explosão de dinamite na mina, já perderam suas casas, pois estas sofreram rachaduras; parte do gado morreu estressado; vacas abortam ou não estão procriando como outrora e as galinhas deixaram de botar ovos (ENRIQUEZ et al., 2011)

Um dos maiores transtornos que os habitantes próximos e os que trabalham diretamente em mineração sofrem é a poluição atmosférica, segundo Silva (2007) a poeira e os gases emitidos pela atividade são provenientes do uso de explosivos, e do trafego de veículos usados na lavra e pelo beneficiamento do minério. Segundo Braga et al., (2007), na cidade de Itabira, o material particulado lançado pela mineradora, na atmosfera pode causar doenças cardiovasculares na circunvizinhança, os efeitos dos poluentes gasosos e o material particulado inalável gerados podem ser comparados ao dos emitidos pelos grandes centros urbanos. A cidade sofre com a mineradora que se encontra nos seus limites, um estudo feito por Braga et al., (2007), mostra que a poluição do ar na cidade está associada a aumentos nos atendimentos de pronto-socorro por doenças respiratórias entre crianças e adolescentes e por doenças cardiovasculares entre adultos.

Quanto a poluição das águas, Pontes et al,. (2013), comenta que a maioria das minerações no Brasil (ferro, calcário, granito, areia, argila, bauxita, manganês, cassiterita, diamante entre outras) contaminam as água através da lama; sendo necessário construção de barragens para o controle da contaminação. Ocorre também a poluição química provocada pelo tratamento do minério ou pela passagem da água pela área de mineração. De acordo com Matta (2001), também ocorre poluição das águas por óleos e detergentes, vindos das oficinas, maquinas, caminhões, e por sólidos suspensos, que podem causar aumento de turbidez, mudança de cor e assoreamento.

Marent et al., (2011), analisando os conflitos ambientais na Serra do Gandarela, concluíram que a mineração de ferro é necessária ao desenvolvimento econômico, mas normalmente, está relacionada ao conflito com a água. Assim, preservar a água é fundamental a vida, uma vez que os recursos naturais estão sendo consumidos a uma velocidade impressionante. Matta, (2001) diz que as contaminações de águas listadas, podem ser controladas por desvios da água; drenagem da lavra; controle de infiltração e sistemas controlados de deposição de pilha de estéril e rejeito. E seu tratamento pode ser feito pela sua recirculação, neutralização, decantação e filtragem com utilização de barragem.

Na maioria dos casos a atividade de mineração também implica no desmatamento e/ou impedimento de regeneração natural. De acordo com Mechi e Sanches (2010), muitas vezes, o solo superficial, que possui maior fertilidade, é removido, expondo os solos remanescentes aos processos erosivos que podem causar o assoreamento dos corpos d'água do entorno. A degradação visual da paisagem é o impacto mais característico da mineração, segundo Matta (2001), as lavras a céu aberto e garimpo provocam a alteração inevitável da topografia do terreno. A lavra em céu aberto possui maior aproveitamento do corpo mineral, gerando grande quantidade de estéril (substâncias minerais que não têm aproveitamento econômico). Quando este não possui uma destinação correta, nos períodos de chuva, ele fica sujeito à remoção e transporte até as regiões mais baixas dos cursos d'água e dos reservatórios, provocando seu gradativo assoreamento (VIANA, 2007). Segundo Pontes et al., (2013), o problema pode ser minimizado com a correta destinação deste material e posteriormente utilizado para reaterro de áreas já mineradas e de tanques de decantação que retenham os sedimentos finos na própria área, preservando a hidrografia.

Tonietto e Silva (2011), estudando a valoração dos danos da mineração de ferro no Quadrilátero Ferrífero, discutem que devido ao potencial da região para a extração de minério, grande parte dos remanescentes da Mata Atlântica dessa região, pertence a 
A mineração em Minas Gerais: uma análise de sua expansão e os impactos ambientais e sociais causados por décadas de exploração

Vanessa Leite Rezende

mineradoras, e considerando o alto grau de ameaça desse bioma, torna-se de fundamental importância a aplicação de multas proporcionais ao dano ambiental causado. Segundo esses autores, em se tratando de grandes empresas, as despesas com controle ambiental na atividade de mineração, incluindo a revegetação de áreas degradadas, são inferiores a $1 \%$ do custo de investimento de uma grande lavra, o que chama a responsabilidade da perícia ambiental a fim de edição de multa em valor que mostre ao minerador pelo menos parte do valor que o meio ambiente possui.

Farias (2002) fez uma síntese dos principais impactos ambientais, de algumas substancias minerais no Brasil, destacando as que causam os principais impactos ambientais. Dentre os casos, as substancias encontradas em Minas Gerais, com seus principais problemas foram: Ferro (problemas com antigas barragens de contenção e poluição de águas superficiais); Ouro (produz rejeitos ricos em arsênio e aumento de turbidez), e Calcário (problemas em áreas de cavernas com impactos no patrimônio espeleológico).

\section{CONSERVAÇÃO X DESENVOLVIMENTO SUSTENTÁVEL}

O Desenvolvimento Sustentável surgiu a partir da preocupação com as mudanças climáticas através dos estudos realizados pela ONU- Organização das Nações Unidas, definindo o conceito de desenvolvimento Sustentável como aquele que atende as necessidades do presente sem comprometer as possibilidades de as gerações futuras atenderem suas próprias necessidades (Barbosa,2008).

Segundo Enríquez (2007), a mineração apenas pode ser considerada sustentável se minimizar os seus impactos ambientais e mantiver certos níveis de proteção ecológica e de padrões de qualidade ambientais, além de garantir o bem-estar socioeconômico no presente.

Cowell et al., (1999) defende que a sustentabilidade na mineração deve ser discutida sob duas perspectiva contrastantes baseadas em aspectos ecológicos, sociais e econômicos, acerca da indústria extrativa mineral. A primeira perspectiva descreve que a extração contínua e crescente de recursos não renováveis, é uma parte necessária das atividades de desenvolvimento sustentável. Já a segunda perspectiva defende que na busca de sociedades sustentáveis, a extração desses recursos deva ser bastante reduzida ou mesmo eliminada. Ou seja, o desenvolvimento sustentável precisa ter como meta a redução na extração de recursos minerais.

A necessidade de uma avaliação sistêmica sobre o uso dos recursos naturais tem sido debatida em conferências sobre o meio ambiente, como na RIO 92, onde foram firmados os primeiro acordos para minimizar a degradação ambiental. Segundo IBRAM (2012), a partir de 2000, a legislação internacional passou a influenciar a legislação trabalhista brasileira, obrigando as empresas a avaliar e mitigar os impactos ambientais e a ampliar o quadro regulatório sobre uso sustentável dos recursos naturais.

Segundo Farias (2002), a atividade mineradora no Brasil é regida por uma série de regulamentações, sendo extensa e conflitante, criando dificuldades na sua aplicação. A crescente concorrência e as exigências do mercado exportador requerem padrões ambientais rigorosos. De acordo com Hilson \& Murk (2000) as regras que regulam a mineração nos países subdesenvolvidos são muito mais frouxas e menos rigorosas do que nos países desenvolvidos. Dessa forma, seguir a legislação local não significa que ocorra uma excelente prática ambiental. Assim, a venda externa funciona como um verdadeiro freio às práticas ambientais predatórias.

O grande aumento da exploração minerária nos últimos anos (após 2010) pode estar relacionado a mudança do código florestal efetuada no ano de 2012 (Meira et al 2016). Até 2012 as duas principais leis ambientais do Brasil (Código Florestal e Código de Mineração de 1960), impuseram restrições ao uso dos recursos naturais por proprietários de terras e empresas. Porém após as grandes empresas e lobbies políticos conseguiram mudar o Código Florestal, o Código de Mineração também se encontra ameaçado (Meira et al 2016; Stickler et al 2013).

\section{CONCLUSÃO}

O estado de Minas Gerais, apesar de anos de explorações minerais, apresenta uma expressiva produção mineral no país, com perspectivas promissoras de expansão. Porém, esse aumento da busca por miné- 
rio está causando a aproximação, cada vez maior, das mineradoras às Unidades de Conservação do estado, o que, somado a falta de ações de planejamento por parte dos poderes públicos e a carência de adoção de procedimentos técnicos adequados no planejamento e desenvolvimento das minas e as deficiências no controle e recuperação ambiental, gera um importante conflito socioambiental e econômico. Desse modo, se estabelece um conflito complexo em relação ao desenvolvimento da mineração e sua sustentabilidade, sendo preciso assegurar o suprimento futuro de minerais e, ao mesmo tempo, garantir a qualidade das condições ambientais, e a sua coexistência de forma sustentável com outras atividades econômicas e de uso do solo.

\section{REFERENCIAS}

BARBOSA, G. S. O Desafio do Desenvolvimento Sustentável. Revista Visões $4^{\text {a }}$ Edição, $N^{\circ} 4$, Volume 1 - Jan/Jun 2008. Disponível em http://www.fsma.edu. br/visoes/ed04/4ed_O_Desafio_Do_Desenvolvimento_Sustentavel_Gis ele.pdf. Acesso em 24/02/2016

BARRETO, M. L. Mineração e desenvolvimento sustentavel: desafios para o Brasil. CETEM/MCT, Brasil. 2001.

BITAR, O. Y. Avaliação da recuperação de areas degradadas por mineração na regiao metropolitana de Sao Paulo. 1997. 185f. Tese (Doutorado). Escola Politécnica da Universidade de São Paulo. 1997

BRAGA, A.L.F; PEREIRA, L. A. A.; PROCÓPIO, M.; ANDRÉ; PAULO, P. A.; SALDIVA, H. N. Associação entre poluição atmosférica e doenças respiratórias e cardiovasculares na cidade de Itabira, Minas Gerais, Brasil. Cadernos de Saúde Pública, v.23, n.4, pp. 570-578. 2007. DOI: http://dx.doi.org/10.1590/ S0102-311X2007001600017

CABRAL JUNIOR, M.; SUSLICK, S. B.; OBATA, O. R.; SINTONI, A. A mineração no estado de são paulo: situação atual, perspectivas e desafios para o aproveitamento dos recursos minerais. Geociências, v.27, n.2, pp. 171-192. 2008.
COWELL, SARAH J.; WEHRMEYER, W. A.; ARGUST, P. W; ROBERTSON, J. GRAHAM S. Sustainability and the primary extraction industries: theoris and practice. Resources Policy v.25, n.4, pp. 277-286. 1999. Doi:10.1016/S0301-4207(00)00003-9.

DEPARTAMENTO NACIONAL DE PRODUÇÃO MINERAL - DNPM. Informe Mineral. Brasília: DNPM, 2014. Disponível em: <http://www.dnpm. gov.br/mostra_arquivo.asp? DBancoArquivoArquivo $=9114>$. Acesso em: nov. 2014.

DINIZ, J. M. F.; REIS, A. A.; ACERBI JUNIOR, F. W.; GOMIDE, L. R. Detecção da expansão da área minerada no quadrilátero ferrífero, minas gerais, no período de 1985 a 2011 através de técnicas de sensoriamento remoto. Boletim de Ciências Geodésicas, v.20, n.3, pp.683-700, jul-set, 2014. Doi: http://dx.doi. org/10.1590/S1982-21702014000300039

ENRÍQUEZ, M. A. R.; FERNANDES, F. R. C.; ALAMINO, R. C. J. A mineração das grandes minas e as dimensões da sustentabilidade. IN: FERNANDES, F. R. C.; ENRÍQUEZ, M. A. R; ALAMINO, R. C. J. (orgs). Recursos naturais e sustentabilidade natural. Grande Minas. v.1. Rio de Janeiro. 2011.

ENRÍQUEZ, M. A, R. S. Maldição ou dádiva? Os dilemas do desenvolvimento sustentável a partir de uma base mineira. Tese de Doutorado em Desenvolvimento Sustentável. Centro de Desenvolvimento Sustentável da Universidade de Brasília - CDS/UnB. Universidade Federal de Brasília. Brasília. 2007.

FARIAS, C.E. G. (2002). Mineração e Meio ambiente no Brasil. Relatório Preparado para o CGEE.

HILSON, G.; MURCK, B. Sustainable development in the mining industry: clarifying the corporative perspective. Resources Policy, v.26, n.4, pp.227-238. 2000. DOI: doi:10.1016/S0301-4207(00)00041-6.

IBRAM. Gestão para a sustentabilidade na mineração: 20 anos de história. 2012. Disponível em: $<$ http:// www.ibram.org.br/sites/1300/1382/00002130.pdf>. Acessado em: Nov. 2014. 
A mineração em Minas Gerais: uma análise de sua expansão e os impactos ambientais e sociais causados por décadas de exploração

Vanessa Leite Rezende

MARENT, B. R.; LAMOUNIER, W. L; GONTIJO, B. M. Conflitos ambientais na Serra do Gandarela, Quadrilátero Ferrífero - MG: mineração x preservação. Revista Geografias, v.7 n.1, pp. 99-113. 2011.

MATTA, P. M. Refexos da mineração na qualidade ambiental das cidades. 2001. Disponível em: http://www.dnpm.gov.br/mostra_arquivo. asp? IDBancoArquivoArquivo=2065. Acessado em: set. 2014.

MECHI, A.; SANCHEZ, D.L. Impactos ambientais da mineração no Estado de São Paulo. Estudos avançados, v.24, n.68, pp.209-220. 2010. DOI: http://dx.doi. org/10.1590/S0103-40142010000100016

PONTES, J. C.; FARIAS, M. M. S.; LIMA, V. L. A. Mineração e seus reflexos socioambientais: estudos de impactos de vizinhança (eiv) causados pelo desmonte de rochas com uso de explosivos. Polemica, v.12, n.1, pp.77-90. 2013

ROESER, H. M. P.; ROESER, P. A. O quadrilátero ferrífero - MG, Brasil: aspectos sobre sua história, seus recursos minerais e problemas ambientais relacionados. Geonomos, v.18, n.1, pp. 33-37. 2010.

SILVA, J. P. L. Impactos ambientais causados por mineração. Revista Espaço da Sophia, n. 8, pp.1-13. Nov. 2007.

SILVA, M. G. S.; SOUZA, M. R. G. Itabira - Vulnerabilidade Ambiental: impactos e riscos socioambientais advindos da mineração em área urbana. XIII Encontro da Associação Brasileira de Estudos Populacionais, Ouro Preto, Minas Gerais, Brasil. 2012.

SOBREIRA, F. G.; FONSECA, M. A. Impactos físicos e sociais de antigas atividades de mineração em Ouro Preto, Brasil. Revista Geotecnia, n 92, pp.5-27. 2001.

SOS Mata Atlântica, INPE. Atlas dos Remanescentes Florestais da Mata Atlântica: período 2012-2013. Relatório técnico. São Paulo, Brasil. 2014.
TONIETTO, A.; SILVA, J. J. M. C. Valoração de danos nos casos de mineração de ferro no brasil. Revista brasileira de criminalística, v.1, n.1, pp. 31-38. 2011

VIANA. M. B. Licenciamento ambiental em minerações em Minas Gerais: Novas abordagens de gestão. Dissertação de Mestrado. Centro de Desenvolvimento Sustentável da Universidade de Brasília-CDS/UnB. Universidade de Brasília. Brasília. 2007 